\title{
INDOOR AIR QUALITY AND ITS HEALTH IMPACTS IN THAME, SAGARMATH NATIONAL PARK, NEPAL
}

\author{
Atindra Sapkota* \\ Sandeep Shrestha \\ Sanjay N. Khanal \\ Department of Environment Science and Engineering \\ Kathmandu University \\ Dhulikhel , PO Box 62250, Nepal \\ *corresponding author \\ Annalisa Cogo \\ Centro Studi biomedici applicati allo Sport \\ Universita di Ferrara, 44100 Ferrara, Italy
}

\begin{abstract}
In many developing world, respiratory problems such as chronic obstructive pulmonary disease (COPD) has been of major concern and is attributed to the indoor air pollution. The aim of this study was to monitor the indoor air quality and assess its health impact on 104 subjects of 35 households of Thame Village Development Committee, Solukhumbu District. It was carried out for nine days in November 2008. In the Kitchen, emission of Carbon monoxide $(\mathrm{CO})$ and Particulate matter $(\mathrm{PM})$ in the size range $\leq 2.5 \mu \mathrm{m}\left(\mathrm{PM}_{2.5}\right)$ were monitored as an indicator of indoor air pollution. The instruments used were UCB particulate monitor and $\mathrm{HOBO} \mathrm{CO}$ meter. Similarly, Spirometer was used to assess the respiratory function. $\mathrm{PM}_{2.5}$, concentration varied between $0.4 \mathrm{mg} / \mathrm{m}^{3}$ and $10 \mathrm{mg} / \mathrm{m}^{3}$. Maximum concentration of about $10 \mathrm{mg} / \mathrm{m}^{3}$ was observed for traditional cooking stove (TCS) with no chimneys. For the modern or improved cooking stoves ICS) with ventilation from pipes and chimneys, the concentrations were below $0.4 \mathrm{mg} / \mathrm{m}^{3}$. Similarly, the average indoor air CO concentration for 8 hours has been found to be between 5 and $30 \mathrm{ppm}$, depending on different stove types. The highest concentration of about $200 \mathrm{ppm}$ was observed at the time of cooking (ca. 2 hours average) using TCS with chimney only. In addition, health spirometry test was performed on 70 subjects of Thame Village Development Committee (VDC) and 34 subjects of different villages and background. The spirometry test indicated that ca. $14 \%$ of the subjects showed mild obstruction whereas ca. 5\% showed moderate obstruction. It has to be noted that despite the recent switch to the alternative cleaner energy source from the polluting solid fuels, the long term exposure in the past might show its adverse effect in the old ages.
\end{abstract}

Keywords: Kitchen, Indoor Air Pollution, TCS, ICS, $\mathrm{PM}_{2.5}$, CO, Spirometry

\section{INTIRODUCTION}

Humans are exposed to the atmospheric contaminants, both gaseous and particulate matter (PM) every second of everyday as we breathe. In case of airborne particulate matter, it has both short term and long term effect on human health, ecosystems and materials. Compare to

https://doi.org/10.15626/Eco-Tech.2010.113 
ecosystem, air borne particulate matter has adverse effect on human health. Study of particulate matter or aerosol is also of importance because of various metals and other toxic chemicals associated with it. In addition, the residence time in the atmosphere as well as the chemical and mineralogical composition of particulate matter depends on the particle size. Generally, smaller particles (about $5 \mu \mathrm{m}$ diameter size) are suspended in the atmosphere for longer time and provide the surface for many of the chemical reactions in the atmosphere, contributing to the high complexity of particulate composition. Furthermore, particles within this range are also respirable. Therefore it is important to quantify the emission of suspended particles in respirable size as well as to evaluate the exposure of public to this size range. Although many studies report that exposure to air pollution harms health, few have examined associations between pollution sources and health outcomes. Notably, not only the particulate matters but also the emission of gases is also significant in terms of study of adverse health effect. Of particular importance is the Carbon monoxide $(\mathrm{CO})$ gas which predominantly has the mobile emission sources. This is because it forms carboxyhemoglobin in blood inhibiting oxygen carrying capacity of the blood.

In terms of exposure, it is more in the developing world than in the developed world. Outdoor air pollution might be the major source of atmospheric contaminants exposure in the developed world. In the developing world, indoor air pollution also predominates in addition to the outdoor ones. This is because, in developing world, majority of the population rely biomass such as dung, wood, crop waste or coal to meet their most basic energy needs. The dependency on such fuels for cooking and heating on open fires or stoves without chimneys leads to indoor air pollution. Several studies have shown that the indoor smoke contains a range of health-damaging pollutants including small soot or dust particles (particulate matter or PM) as well as gaseous pollutants such as carbon monoxide (CO), nitrous oxides, sulphur oxides, formaldehyde and polycyclic organic matter including carcinogens such as benzo[a]pyrene [1]. The problem of IAP is even sever in the case of poorly ventilated kitchens which is common in most of the developing countries. Notably, in most of the developing world, exposure is particularly high among women and children as they spend most of their time near the kitchen causing widespread eye and respiratory problems [2].

Several studies have shown that acute lower respiratory infections (ALRI) among children under five, chronic obstructive pulmonary disease (COPD) among women and lung cancer are the health impacts of greatest public health concern [3]. Furthermore, it has been estimated that the indoor air pollution from biomass burning is responsible for significant deaths due to pneumonia, COPD and lung cancer $[2,4]$. Women who are exposed to indoor smoke from biomass burning suffer highly from COPD than with women who use electricity, gas and other cleaner fuels for cooking and heating. Similarly, Children exposed to indoor smoke are more than twice as likely to suffer from pneumonia than children not exposed [5]. Additionally, exposure to firewood smoke in poorly ventilated conditions might increase the chances of young children suffering from ALRI by $100-400 \%$. It has to be noted that despite the recent switch to the alternative cleaner energy source from the polluting solid fuels, the long term exposure in the past might show its adverse effect in the old ages.

In the context of Nepal, especially in rural areas, fire wood is the main energy source for cooking, heating and lighting. Generally, firewood is used in an open-hearth without a chimney. This has caused indoor air pollution problems in the rooms affecting the health condition of the residents. The severity of the problem and the segment of the population most affected can be seen by the fact that on an average, women in rural Nepal spend more than 
$90 \%$ of the cooking period within two meters of the cooking stove and spend about five hours a day near such stoves [6]. Though the United Nations Development Program (UNDP) and a number of other organizations are working in installing ICS and abating the health problems, only little work has been done to quantify the problems associated with indoor air quality (IAQ) [7]. It has been realized that the assessment of improvement in IAQ by the modification of the open-hearth is necessary.

It is well documented that the air pollution from ambient sources continues to adversely impact human health in all over the world. A significant number of epidemiological studies have identified an increase in occurrence of adverse health effects associated with exposures to mobile source emissions. Some of these adverse effects include asthma, other respiratory diseases, cardiovascular effects, cancer, developmental effects, and even mortality. In addition, many millions more may be exposed to mobile source exhaust through their occupations, personal activities, or the location of their home, school or office near major roads. Similarly, earlier studies on respiratory illness and air pollution have shown that the prevalence of chronic cough with chronic phlegm rose steeply with, age, and was greater among women than men. However, as mentioned earlier about IAQ in developing world it is necessary to identify a location which is relatively free from the vehicular emission. In viewing this, the Himalayan region is a suitable place to separate the effects due to IQA from the vehicular emission.

Therefore, Sagarmatha National Park (SNP) provides the excellent location for the study of impact of indoor air pollution because of many reasons. Because of the increase in tourism and therefore the income of local people as well as the effort of restoring forests and saving energy, local people have switched to the alternative cleaner energy and ICS including electric heater. However, old practices of using solid fuels and TCS could still be seen. In addition, this area is free from major pollutant sources such as vehicles, industries which are common in urban area. Therefore, SNP is best suitable for assessing exposure impact of both previous and present emissions.

The main objective of this study is to assess the indoor air pollution and health impact of the emissions from different types of cooking stoves. As mentioned earlier, the emission of $\mathrm{CO}$ is the indicator of incomplete combustion of biomass burning which also releases range of gaseous pollutants including formaldehyde and polycyclic hydrocarbons. However, the measurement of different organic gaseous products is difficult in terms of financial and analytical resources available. Therefore, the best suitable parameter representing the emission of above mentioned gaseous pollutants is $\mathrm{CO}$. Hence, the parameters chosen for assessing the IAQ were $\mathrm{CO}$ and $\mathrm{PM}_{2.5}$.

\section{MATERIALS AND METHODS}

\subsection{Study area}

The study area chosen is Thame VDC, Solukhumbu District, Nepal $\left(27^{\circ} 49^{\prime} 46.84^{\prime \prime} \mathrm{N}\right.$, $86^{\circ} 38^{\prime} 59.76^{\prime \prime} \mathrm{E}$, and $12,472 \mathrm{ft}$ asl) (Figure 1). It was carried out for nine days in November 2008. Out of 35 households, people are living only in 27 households with total 80 subjects (people above 14 years of age participating in the health assessment). However, only 70 subjects participated in the health assessment. Additionally, 34 participants from different background also participated. 


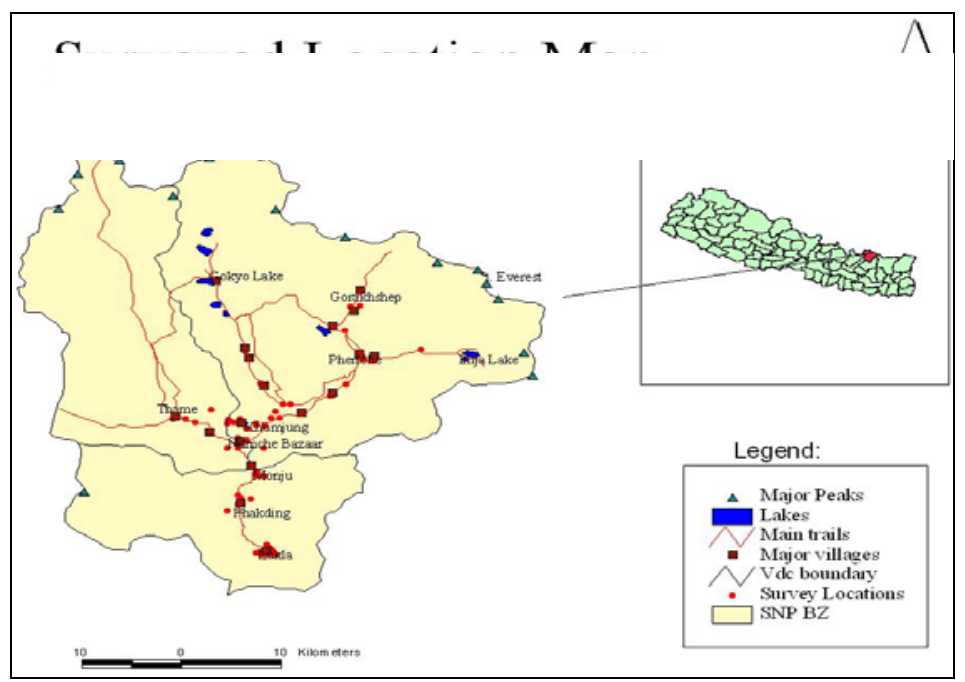

Figure 1: Map of SNP in Solukhumbu District, Sagarmatha National Park (SNP) and the Thame VDC

\subsection{Analytical methods}

In the Kitchen, emission of Carbon monoxide (CO) and Particulate matter (PM) in the size range $\leq 2.5 \mu \mathrm{m}\left(\mathrm{PM}_{2.5}\right)$ were monitored as an indicator of indoor air pollution. The instruments used were UCB particulate monitor and $\mathrm{HOBO} \mathrm{CO}$ meter (University of California Berkley, USA). The HOBO CO meter has two channels i.e $\mathrm{C} 1$ and $\mathrm{C} 2$ with different sensitivities. The concentration ranges that could be monitored by $\mathrm{C} 1$ and $\mathrm{C} 2$ are between $0-125 \mathrm{ppm}$ and $0-500 \mathrm{ppm}$, respectively.

The UCB sampler was placed in the kitchen $1.5 \mathrm{~m}$ above the floor i.e. the height relating approximately the breathing height of a standing woman and $1.0 \mathrm{~m}$ from the edge of the stove. Any changes in distance were recorded on the sampling data form. The details of this protocol are developed by University of California at Berkeley and are available at http://ceihd.berkeley.edu/heh.IAPprotocols.htm. The volume of the kitchen was noted and the average volume of the kitchen was $30 \mathrm{~m}^{3}$.

Similarly, Spirometer was used to assess the respiratory function (Handheld, MicroLoop, Micro Direct Inc. USA). Spirometry is a method of assessing lung function by measuring the volume of air the patient can expel from the lungs after a maximal expiration. Each subject was allowed to rest for at least 30 minutes before performing the spirometer test.

\section{RESULTS AND DISCUSSION}

\subsection{CO emission}

The maximum, 8 hours average and 2 hours average concentration of $\mathrm{CO}$ observed in the monitored households are shown in Figure 2. The average cooking time was found to be around 2 hours and therefore presented as the emission during that time. The difference in the maximum concentration observed during the whole monitoring period is due to the different types of cooking stoves used in the study area (Figure 2) such as ICS and TCS. Also seen was the use of electric heater in few houses but having no effect on direct emission of $\mathrm{CO}$, it was 
excluded from the study. To signify the effect of different stove types on $\mathrm{CO}$ emission, the concentration of CO for ICS and TCS were shown separately in figure 3 and 4.

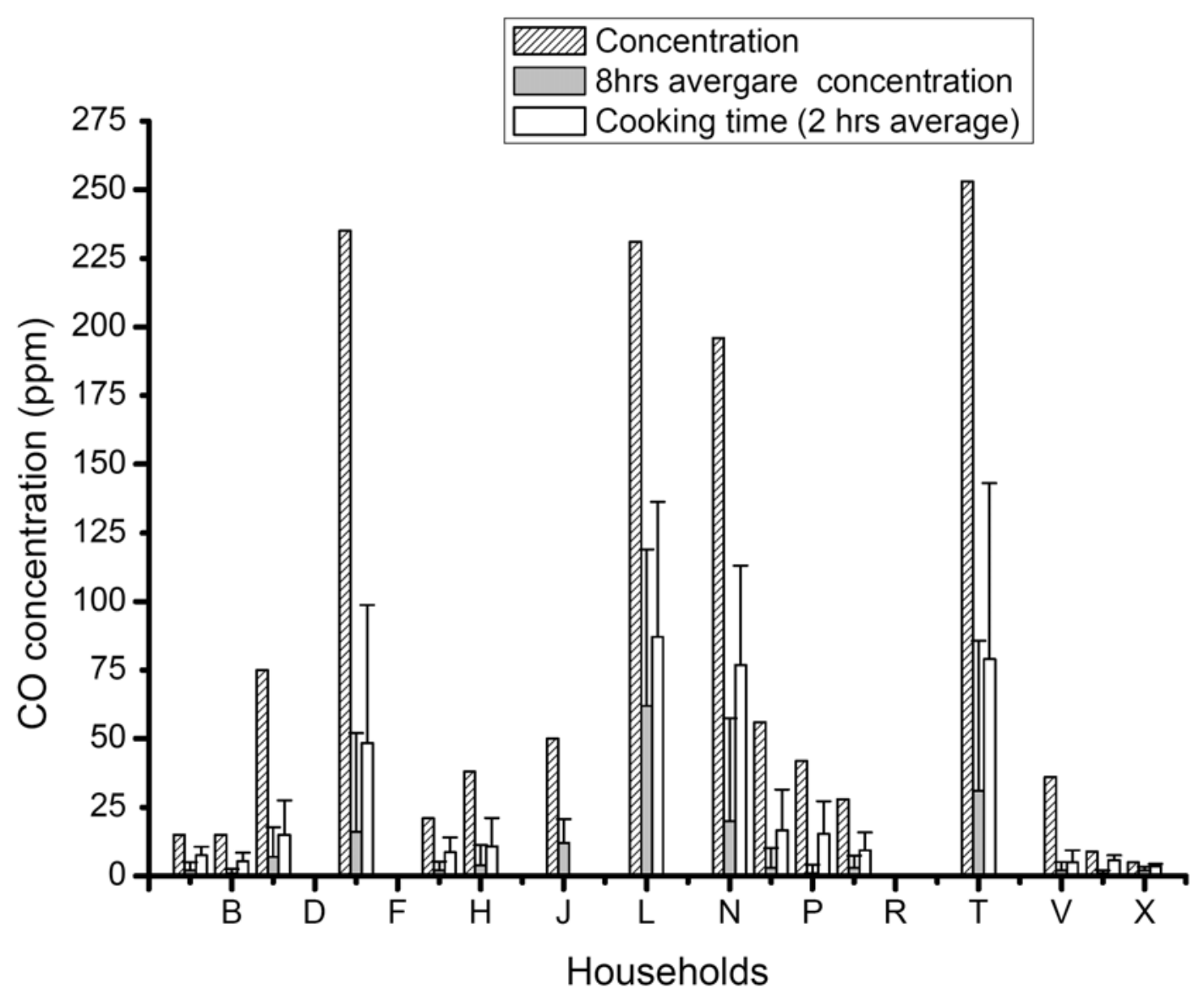

Figure 2: Peak concentration, 8 hrs average concentration, and 2 hrs cooking time average concentration in the Thame VDC, SNPZ, Nepal.

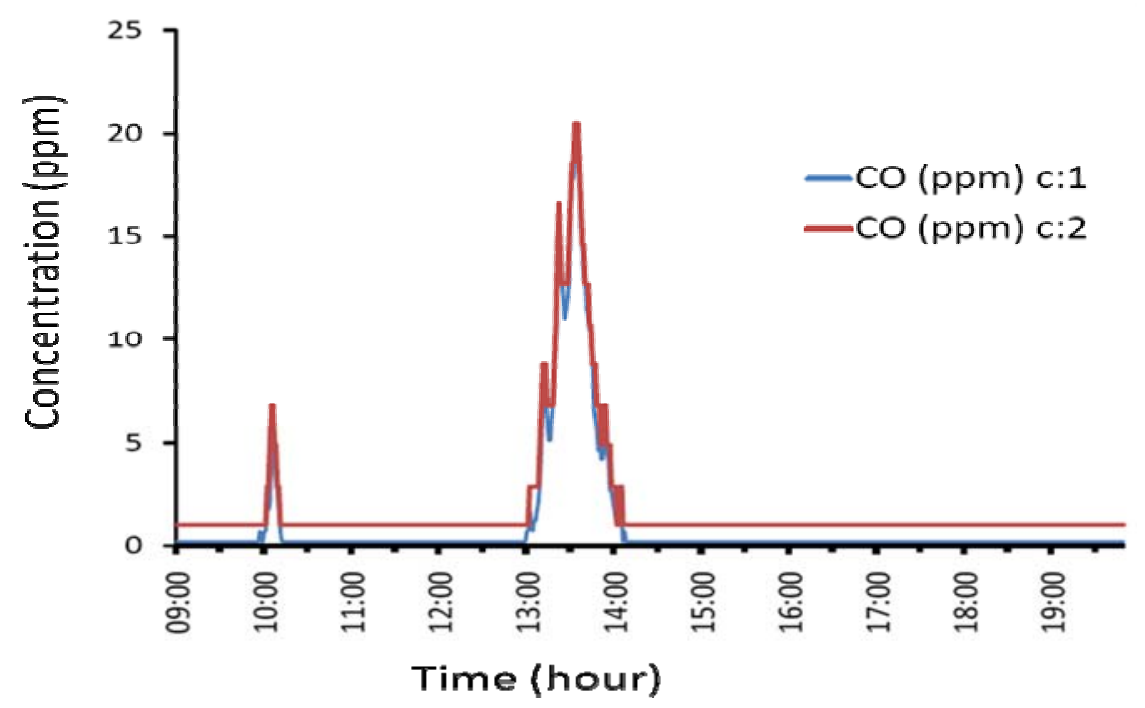




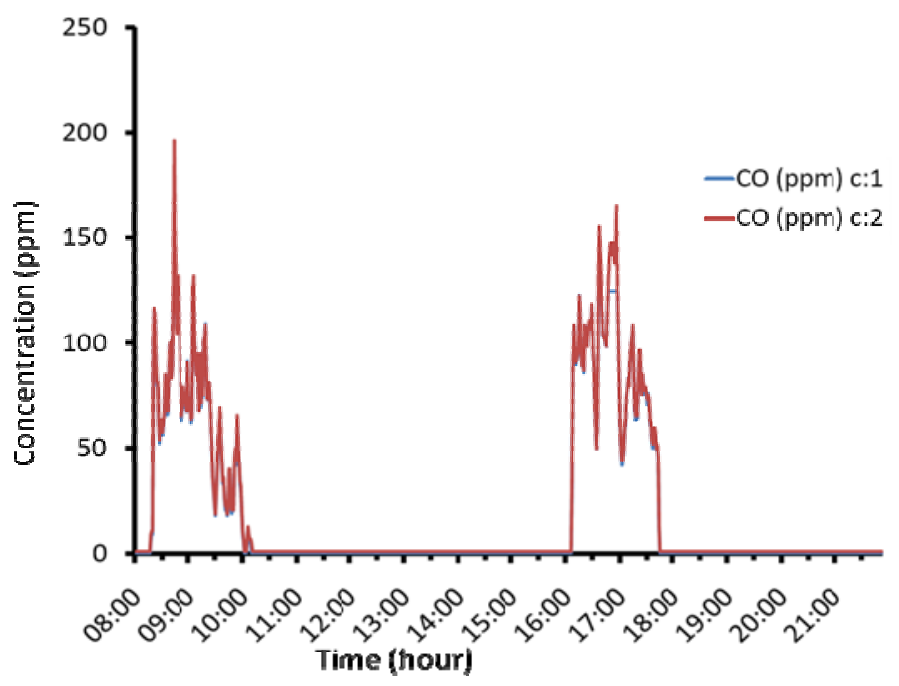

Figure 4: Concentration of CO (ppm) emitted from the Traditional Cooking Stove (TCS)

The average indoor air CO concentration for 8 hours has been found to be between 5 and 60 ppm, depending on different stove types (Figure 2). The highest concentration of $60 \mathrm{pmm}$ ( $8 \mathrm{hrs}$ average) was observed in the case of TCS where the chimney was not available. Notably, the no. of houses with TCS without chimney were negligible. Furthermore, most of the emission for 8 hours is within the range of $10 \mathrm{ppm}$. Similarly, the highest concentration of about $200 \mathrm{ppm}$ was observed at the time of cooking using traditional stoves with chimney only. The minimum concentration was recorded while no cooking was done as well as when the electric heater was used for cooking. The emission of $\mathrm{CO}$ from three types of stoves at the time of cooking (approx. for $2 \mathrm{hrs}$ ) and an average $\mathrm{CO}$ concentration (8hrs) emitted from them are shown below (Table 1).

Table 1: Concentration of CO based on different stove types.

\begin{tabular}{|c|c|c|c|}
\hline Duration of CO monitoring & $\begin{array}{l}\text { Metal stove with pipe } \\
\text { and Chimney (ICS) } \\
(70 \% \text { household) }\end{array}$ & $\begin{array}{l}\text { Stove with pipe only } \\
\text { (ICS) } \\
(10 \% \text { household) }\end{array}$ & $\begin{array}{l}\text { Stove with Chimney only } \\
\text { (TCS) ( } 20 \% \text { household) }\end{array}$ \\
\hline $\begin{array}{lrr}\text { Average } & \text { indoor } & \text { air } \\
\text { concentration } & (8 & \text { hrs } \\
\text { average })(\mathrm{ppm}) & & \end{array}$ & 5.00 & 15.00 & 30.00 \\
\hline $\begin{array}{l}\text { Average indoor CO } \\
\text { concentration (cooking } \\
\text { time: } 2-3 \mathrm{hrs})(\mathrm{ppm})\end{array}$ & 10.00 & 20.00 & 200.00 \\
\hline
\end{tabular}

The average 8 hours concentration is most of the time within the range of allowed concentration of ca. $50 \mathrm{ppm}$ for 8 hours time weighted concentration (NIOSH [8], OSHA [9], USA ) except at one case where the TCS was used. Despite that, $8 \mathrm{hrs}$ average concentration for TCS was still within the range of NIOSH and OSHA. It has to be noted that despite the 
lower concentration observed (10 ppm) due to masking of concentration for longer average for $8 \mathrm{hrs}$, the effect of peak emission and exposure effect for short time could not be neglected. This is specially important in the case of repeated short term exposure. Thus, in the case of TCS, the repeated exposure to the enhanced concentration (ca. $200 \mathrm{ppm}$ for $2-3$ hours) could lead to the severe deterioration of respiratory system and associated sickness such as asthma and COPD. The average 8-hrs time-weighted concentration agrees well with other similar studies from rural Nepal (ca. $3-18 \mathrm{ppm}$ for ICS and $9-39 \mathrm{ppm}$ for TCS) [10] except in few cases. This is possibly due the difference in climatic condition and geographic area. Compare to other areas of similar studies, our study area is in The Himalayan region which demands continuous heating of the building inside. Therefore, there is less ventilation option available and though the windows are present they were kept closed most of the time and opened less even during cooking. This might be one possible reason for increased concentration of $\mathrm{CO}$ monitored. It has been shown that despite the higher concentrations near the stove, concentrations of $\mathrm{CO}_{2}$ was significantly lower in the room indicating that the effect could be reduced by increasing the size of the room, and improved ventilation and cooking practices [11]. In addition to the replacement of the TCS with the ICS, use of exhaust fans in the kitchen will reduce the concentrations of the pollutants significantly.

\subsection{PM $\mathbf{P M}_{2.5}$ emission:}

The concentration of $\mathrm{PM}_{2.5}$ varied between $0.4 \mathrm{mg} / \mathrm{mg}^{3}$ and $10 \mathrm{mg} / \mathrm{m}^{3}$. The mmaximum concentration of about $10 \mathrm{mg} / \mathrm{m}^{3}$ was observed for TCS with no chimneys. In the case of TSC with chimneys the concentration were in the range of $1 \mathrm{mg} / \mathrm{m}^{3}$. This indicates that just using the simple ventilation system can reduce the effect of particulate matter by ten folds. For the ICS with ventilation from pipes and chimneys, the concentration was below $0.4 \mathrm{mg} / \mathrm{m}^{3}$. Earlier studies on emission from TCS and ICS, similar concentrations of $\mathrm{PM}_{2.5}$ were reported for both types of cooking stoves in other parts of rural Nepal such as Dolkha, Dang and Ilam [10].

\subsection{IAQ and health effect}

The results obtained on health assessment of the subjects are shown in figure 5 and 6 .

\section{Population and respiratory obstruction}

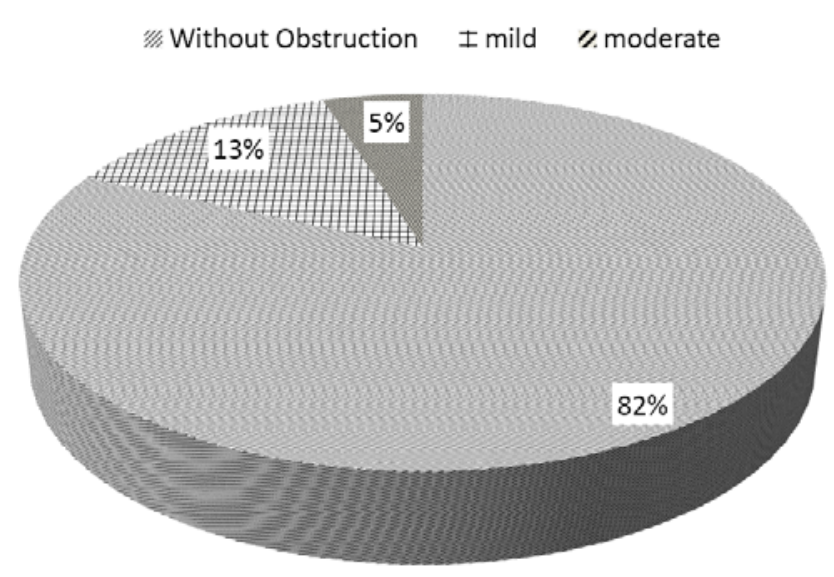



test.

\section{Population with Mild Obstruction}

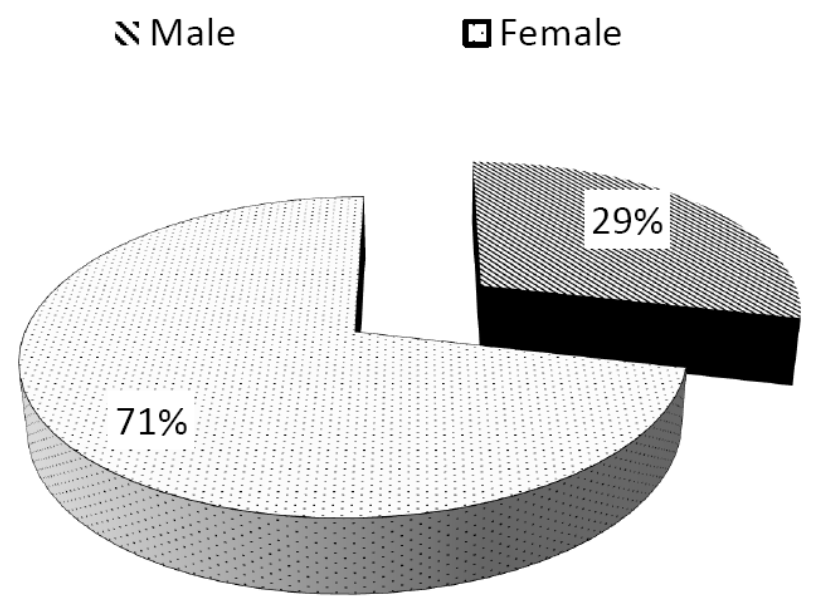

Figure 6: Percentage of male and female having mild obstruction

The spirometer test indicates that majority of the population $(82 \%)$ have no respiratory obstruction. Notably, figure 5 and 6 also indicate that out of the $18 \%$ of the population $71 \%$ is women. This is clear that women are the one to spend most of their time in the kitchen and are thus affected by the IAQ. Similar studies in other parts of the developing world have also shown that the women and children suffer most by the IAQ [2, 4]. Despite having ICS replacing the TCS in the kitchen, earlier exposure to the IAQ could be the cause of the respiratory obstruction. However, detailed study is still required to determine the extent of respiratory problems and differentiate from the present one to the past.

\section{CONCLUSION}

In this research, we investigated indoor air pollution in the houses of Thame VDC, Nepal which is unaffected by the mobile emission sources. The results showed that the emission of $\mathrm{CO}$ was dependent of the stove types and the ventilation system used. Therefore the improved stoves with effective ventilation could help to reduce the indoor CO and PM. Additionally, the results also indicated that the female population has higher chances of having COPD because they spend more time in the Kitchen.

\section{ACKNOWLEDGEMENT}

This study was carried out within the framework of the Ev-K2-CNR Project in collaboration with the Nepal Academy of Science and Technology (NAST) as foreseen by the Memorandum of Understanding between Nepal and Italy, and thanks to contributions from 
the Italian National Research Council and the Italian Ministry of Foreign Affairs. Additionally, we would like to thank Sagarmatha National Park (SNP) and Department of National Park and Wildlife Conservation (DNPWC), Nepal.

\section{REFERENCES}

[1] WHO, 2002. World Health Report: Reducing risks, promoting healthy lives. WHO Press, World Health Organization, Geneva, Switzerland.

[2] Schei, M.A., Hessen, J.O., Smith, K.R., Bruce, N., McCracken, J., and Lopez, V., 2004. Childhood asthma and indoor wood smoke from cooking in Guatemala. Journal of Exposure Analysis and Environmental Epidemiology 14 (S-1), 110 - 117.

[3] WHO, 2005. Indoor Air Pollution and Household Energy Monitoring: Workshop Resources, World Health Organization, Geneva, Switzerland.

[4] Balkrishnan, K., Sambandam, S., Ramaswamy, P., Mehta, S., and Smith, K.R., 2004. Exposure assessment for respirable particulates associated with household fuel use in rural districts of Andhra Pradesh, India. Journal of Exposure Analysis and Environmental Epidemiology 14 (S-1), 14 - 25.

[5] Smith, K.R., Mehta, S., and Feuz, M., 2004. Indoor smoke from household use of solid fuels.' In: Comparatice quantification of health risks: The Global burden of disease due to selected risk factors, Ed.: Ezzati M., Lopez, A.D., Rodgers, A. and Murray, C.J.L., vol. 2, 1435-93. Geneva: World Health Organization.

[6] Reid H. F., Smith K.R. and Sherchan B., 1986, Indoor smoke exposures from traditional and improved cook stoves comparisons among rural Nepali women. Mountain Research and Development, 6 (4) $293-304$.

[7] Rijal, H.B., Yoshida, H., Miyazaki, T., and Uchiyama, I., In: Proceedings of the $10^{\text {th }}$ International conference on indoor air quality and climate (Indoor Air 2005): Indoor air pollution from firewood combustion in traditional houses of Nepal. September 2005., Beijing, China, pp. 3625 - 3629.

[8] NIOSH (The National Institute for Occupational Safety and Health), USA, www.cdc.gov. last viewed on 17 February, 2010.

[9] OSHA (Occupational Safety and Health Administration), USA, www.osha.gov. last viewed on 17 February, 2010.

[10] ENPHO, A report on: Assessment of effectiveness of improved cook stove in reducing indoor air pollution and improving health, April 2008, Nepal.

[11] Isobe, Y., Yamada, K., Wang, Q., Sakamoto, K., Uchiyama, I., Mizoguchi, T., and Zhou, Y., 2005. Measurement of indoor Sulphur dioxide emission from coal-biomass briquettes. Water, Air, and Soil Pollution 163 (1-4), 341-353. 